her own hands. A violent attack of acute dyspepsia, which a single dose of quinine seemed to aggravate, came on and continued for two weeks by which time the patient was greatly exhausted and emaciated. After this he began to recover, at first slowly then rapidly gaining strength till five months a ter the first attack at home, he is quite well and strong. Latterly, he has resumed quinine in small doses but intends in future to keep out of the way of infection. About 60 injections were given each in two drachms of fluid by an ordinary serum syringe; both the syringe and solution having been previously boiled no puncture became septic. Anæsthesia lasting for weeks was caused by the quinine in the neighbourhood of the punctures.

Castlederg, co. Tyrone.

\section{THE TECHNIQUE OF THE EXAMINATION OF SPUTUM FOR TUBERCLE BACILLI FULLY DESCRIBED.}

BY CHARLES GASKELL HIGGINSON, M.A., L.R.O.P. LOND., IATE ASSISTANT MEDICAI SUPERINTENDENT, CROOKSBURT OPEN-AIR
SANATORIUM.

THE examination of sputam for the tubercle bacillus is not dificult to do well if the observer has been well taught and has a good microscope; but if these conditions be absent the results are most unsatisfactory. I regret to say that in my judgment none of the many text-books that $I$ have consulted (except Dr. Charles H. Melland's "Clinical Manual ") goes into sufficient detail on this point. Therefore I venture to support Dr. Melland's attempt at detailed exposition and proceed to describe with even more detail my own practice as I learned it from Mr. Roland A. Stevenson at Pinewood, near Wokingham. I take off the cover from the little glazed saucer in which the fresh sputum lies; then, with a pair of sharp-pointed forceps, I make a sudden snatch at the most purulent part of the sputum. Thus I get at the end of the forceps a tiny bead of sticky sputum. I then take a bright, clean, glass slide, rub it over with washleather, and write on its lower end with one of the pencils made by Faber for marking glass or earthenware the name or number of the patient and the date of examination. On this slide with the forceps I thoroughly tease out the tiny bead of sputum, so that in the centre of the slide there is the thinnest possible film of sputum spread over a circle of about half an inch in diameter. The points of the forceps are then heated red-hot in the flame, plunged into a cup of cold water, and dried on a clean cloth in readiness for future use. The film is often seen to be quite dry, but, if not so, I hold the slide with a thumb and forefinger at each end and pass it once or oftener, film upwards, over the flame of a spirit lamp, taking care by touching the bottom of the slide with a finger, that it shall not be made any hotter than the finger can bear. Having done this until there is no more moisture to be seen in the film, I lay the slide, film upwards, upon a flat surface. I then take in a pipette a few drops of carbol-fuchsin solution and drop them on to the film so that it is just covered, the solution consisting of the following ingredients : fuchsin, one gramme; absolute alcohol, 15 cubic centimetres ; and carbolic acid solution ( 5 per cent.) 85 cubic centimetres. I then pass the slide, film upwards, through the flame of the spirit lamp as before; at the first passage the lamp deposits a watery mist on the cold slide; at the second or third passage this vanishes and at times the drops of carbolfuch-in solution can be seen to send up from the slide a little cloud of water vapour, though it does not and must not boil; the finger, touching the slide where it has been most expo-ed to the heat of the flame, ought to feel the slide to be about as hot as is comfortably bearable. Then the slide should be laid on a flat place, say across a glass trough of about the size of a common pen tray, such as is used to lay pipettes in. After about seven minutes the carbol fuchsin has done its work and stained the film a bright crimson. Then I take the slide to a white basin and turn on a tap of cold water with a narrow orifice on to which has been fitted 18 inches of indiarubber tubing of about the calibre of the tube of a Higginson syringe. The water should flow in a gentle stream exactly like the stream that is obtained when one of those syringes is used as a syphon; the crimson stain is then washed off in this running stream till no more pinkness remains in the water that runs off the slide. I then take one of Baird and Tatlock's glass slide-baths, each of which is about four inches long, one and a half inches broad, and four inches deep, and holds eight slides upright, each in a separate groove, and fill it two thirds full of a 25 per cent. aqueous solution of strong sulphuric acid. Into this bath I put the slide, inscription upwards, so that the film is covered. The film should be decolourised so much that when the slide has again been washed under the stream there shall appear agrinst the white background of the basin only the very faintest rose tint. This usually happens after about a minute's immersion in the sulphuric acid solution; but if, after washing with the stream from the rubber piping, a deeper tint than this is seen, the slide must be immersed again in the acid solution. On the second immersion the decolourisation proceeds with surprising rapidity, so that the slide should be washed and re-examined in ten seconds. After the slide has been washed under the tap much of the colour of the films commonly returns which the acid bath had temporarily quite removed. Then the slide with the faint rosy film is immersed in another similar slide-bath containing a saturated aqueous solution of methylene blue. (I venture to disapprove of the practice of trying to decolourise and to counterstain simultaneously by the use of a mixture of sulphuric acid and methylene blue.) In about three minutes the slide is taken out and washed under the stream from the tap. The film is then seen to be of a bright blue colour and slide is laid flat on the glass trough. The acid solution and the methylene blue solution are then poured back into their bottles and they may be used perhaps 50 times again. The slide is then dried with a clotb, the film being untouched, and the drying is completed for the slide and the film by passing the slide over the spirit lamp as previously described; or a hot air bath may be used by heating a metal slide rack on wire gauze on a tripod over a spirit lamp. A drop of cedar oil is placed on the film and the microscope is brought out. The microscope is fitted with an Abbe condenser so that the light may be concentrated on the film; it has also three object lenses, of one inch, one-sixth of an inch, and one-twelfth of an inch respectively, all of which are fixed on a nose-piece and can by mere rotation, without any screwing and unscrewing, be adjusted in tarn to the central axis of the barrel and the eye-piece. The blind is drawn down and an electric light is turned on, fitted with a paraboloid reflector so as to illuminate the microscope's mirror. The slide is then brought on to the stage, which is itself moveable by a couple of coarse adjustment screws, along an ordinate and an abscissa at right angles to each other, up and down and from side to side. It is then focussed by the one inch lens. A bundle of blue fibres should be selected and placed in the centre of the field. Then the one-twelfth inch lens should be switched on and by the coarse adjustment should be gently lowered, till the oil seems to rise and touch the lens. The lens is then not near enough to the slide for clear vision, and we look down the eye-piece, while with the fine adjustment we gently lower the lens till the blue fibres are focussed. The Abbé condenser should be brought close up to the slide so as to illuminate it as brightly as possible. Amidst the blue fibres and cells are seen little pink rods, some straight, most slightly curved, each about five times as long as it is broad, often two together, often many in a clump, each in appearance from one-eighth to one-sixth of an inch long. These are the tubercle bacilli, which, once stained by the carbol fuchsin, are not, as the other cells are, decolourised by the sulphuric acid nor counterstained by the methylene blue. Before I put the microscope away I wipe off the cedar oil from the lens with a silk handkerchief. If the slide is to be kept the film should be dried with blotting-paper and mounted at once in Canada balsam. If the process of counterstaining by the methylene blue be omitter, the bacilli are seen merely stained a deep crimson in a field of a faint rose pink. The two methods are perhaps equally good and I habitually use both for every specimen; on the pink slides there are usually more bacilli seen, but the blue counterstain affords the more striking demonstration. The crimson bacilli ought to stand out against the blue background almost as clearly as they are represented in the pictures of Bury's "Clinical Medicine" or Hutchinson and Rainy's "Clinical Methods."

In my experience the search for the bacilli in the sputum of consumptive patients is commonly quick, sure, and easy if the one-twelfth inch lens be used, with the oil immersion ; if 
the one-sixth inch lens be used, the student will be discouraged and a good clinical resource will be discredited. I am told that there are laboratories, especially in Germany, where there is a better and quicker technique than what I have described and a wiser and more thorough elaboration of detail. If so, surely the fullest details of that better technique ought to be laid before us; but meanwhile I venture to hope that the method which I practise is worthy of being recorded in full detail for such of my medical brethren as care to reacl this memorandum. Finally, when I have been beyond the reach of slide-baths, fixed white basins with outflow pipes, electric lamps, paraboloid mirrors, and water taps laid on in the laboratory, I have managed very well with common little glass tumblers, a white washhand basin from a bedroom, an eighteen-penny paraffin lamp with its tin reflector, and a Higginson's syringe, wherewith I syphoned from a large bowl placed on a shelf the gentle stream of water which after washing my slides was caught in a whiteware slop-pail standing on the floor. Thus, if only the microscope and the method be available the technique can be carried out in an ordinary workroom, the accessories being improvisable by the ingenuity of the microscopist.

Birmingham.

\section{Clinital allotes:}

\section{MEDICAL, SURGICAL, OBSTETRICAL, AND THERAPEUTICAL.}

THE USE OF TURPENTINE IN RENAL HYDATIDS.

By E. Mackey, M.D.Lond, M.R.C.S. Eng., M.R C.P. Lond. SENIOR PHYSICIAY TO THE SUSSEX COUNTY HOSPITAL, ETC.

A MAN, about 60 years of age, came to me in December, 1904, complaining most of extreme flatulent distension, which was worse at night, causing insomnia, mental depression, and a general condition of illness unfitting him for responsible work. Incidentally he mentioned that for 15 years past he had had occasional attacks of colic followed by the passage of hydatids in the urine, usually once or twice in 12 months. The last attack occurred in October and was very severe, so that his condition was critical and he had not yet recovered strength after it, though now almost free from pain. The urine (specific gravity 1034) deposited urates and uric acid. As he had been told by several advisers that no medicines affected hydatids he asked for no treatment in that direction, although a tumour of the size and shape of a large orange could be felt deep in the left kidney region; it was moveable, smooth, not tender, and without definite thrill. The prescriptions which he showed were mainly for flatulent distension and when this was relieved (as it was by regulation of diet, sulphites, cachets of charcoal with thymol, validol, \&c.) he commenced (on Dec. 13th) to take 15 minims of ol. terebinthinæ mixed with liquor potasmucilage, and liquorice night and morning. He contiuued this as the main treatment and was able in February of this year to return to his duties which involved administration of a large institution. All the symptoms were better and the lump was smaller.

On March 2nd he forwarded by post a sample of hydatid vesicles varying from the size of a pea to that of a hazel-nut "passed with but little pain" ; the turpentine had been continned, he said, "with the exception of very few days" ; the general health was improved. On April 10th more were passed, described as "smaller and darker," and the medical man who had known about the cyst before the patient's visit to Brighton expressed himself as "very surprised and pleased to find it only half its former size." "The letter adds: "I am also very much better re dyspepsia and flatulence," confirming my opinion that the severe attacks which for a long time occurred about $2 \mathrm{~A} . \mathrm{M}$. were connfcted wi'h mechanical pressure on the colon (now relieved). Early in July, turpentine having been continued, he reported " no sign now of kidney trouble though there is a small lump; the doctor says it is so small and diminishing so continuounly I need not go to him again. ...... I have been travelling in Ireland lecturing three times a day; all indigestion anr flatulence have left me. I really feel a new man." His expressions of grateful thanks I interpret as showing the very suffering state which he had been in and the remark able benefit that he had obtained apparently from the remedy which I take the opportunity of again bringing into notice.

Renal hydatids are so far rare that the late Sir W. Roberts (second edition) could only refer to 63 cases, in 20 of which "recovery was assumed." He mentions that turpentine was giren in a large number of those recorded but finds "little evidence of its beneficial influence." This remark bas no doubt influenced practice, and Whitla (fourth edition) goes so far as to say "the wild statements about efficacy of kamala, turpentine, \&c., have been proved devoid of truth.' My own opinion of its still being worth trial-especially in renal cases-was derived from conversation with Dr. Warburton Begbie, no mean observer, but I have not been able to find the subject mentioned in his writings. Valeat quantum.

Hove, Brighton.

\section{A NOTE ON THREE UNUSUAL MIDWIFERY CASES IN ONE WEEK.}

By H. H. Robinson, M.R.C.S. EnG., L.R.O.P. Lond.

THE note on these three cases has been written chiefly on account of their extreme rarity, as none of them pre sented any extraordinary difficulty in treatment. They occurred in a general practice within seven days.

On Jan. 14th I was called by a midwife to a case which she was attending and on arrival 1 found that the child had been born some little time and that the mother was apparently dying. There was a huge mass outside the vulva, lying on the bed, which proved to be the uterus completely inverted and extruded as far as the vaginal vault. To the surface was attached the placenta, very firmly adherent, as were also the membranes. The patient was suffering from profound shock, so I first administered strychnine, digitalin, and "ergot aseptic" hypodermically. She rallied a little, so I proceeded to strip off the placerta and membranes and then after considerable difficulty replaced the uterus. The first portion of the re-position was easy but the swollen state of the fundus caused much trouble. Shortly after this my colleague, Dr. James Pinkerton, arrived and for tho hours we did all in our power to relieve the extreme shock but with no success, the patient, who was a bipara not much over 20 years of age, dying at the expiration of that time. It was strongly denied that traction on the cord in the attempt to remove the adherent placenta was the cause of the accident.

The next case was one of triplets, all girls, all footling presentations, and the unuscal feature of the case was that only one placenta was present with thre amniotic sacs. I examined the placenta carefully but found no evidence of the coalescence of two.

The third case occurred six days later and on arriving I found that the child bad been born about two hours. 'There was a large bluish tumour protruding from the vulva, larger than a fotal head at term, which consisted of the cervix uteri enormously swollen. The woman had a very tight perineum and evidently in straining had forced the uterus down and the vessels had become constricted. Efforts to renuce the cervix without anæstheria were unsucceseful chloroform was then administered, after which the rtduction was effected and later in the day the cervix appeared quite normal.

Birkenhead.

A CASE OF CASAREAN SECTION

By Alfred E. Ash, M.D. Vict,, M.R.C.S. EnG.

BEING recently requested to attend an inmate of the South Molton Workhouse I found that the patient, a primi. para, aged 18 years, had been in labour for several hours. On examination a hand was felt to be presenting low in the vagina and I therefore at once sent for $\mathrm{Mr}$. H. J. Smyth (the official deputy of the gentleman for whom I was acting) to anæsthetise the patient as a preliminary to version. Chlornform was administered and I then found that the case was one of extreme pelvic contraction in the anteroposterior diameter, and although after considerable difficulty a foot was brought down, yet it was impossible 